\title{
The Impacts of Learning Motivations on Colleges Students' English Learning and Implications on College English Teaching
}

\author{
Wei Liu \\ School of Foreign Languages, Jilin Agricultural University, ChangChun 130118, China \\ 29897259@qq.com
}

Keywords: Learning Motivations, English Learning, College English Teaching

\begin{abstract}
English, as a world language, can play a very significant role in both employment and life for college students, but many college students complain about their failures in English learning. There are many factors which can influence college English learning, among which learning motivation can be ignored. This paper will discuss the impact of learning motivation on colleges students' English learning and the implication on college English teaching.

English, as a world language, can play a very significant role in both employment and life for college students. However, after years of English learning, college students' achievements and interests in English are not satisfactory in our country. There are a lot of reasons, of which learning motivation is an important factor that can not be ignored. Learning motivation is an intrinsic drive of the students and social and educational requirements on learning reflected in the students' mind. The main components of learning motivation are learning consciousness and interest. Once students have consciousness to learn,they will burst out with great enthusiasm, a strong spirit and positive action. This paper will discuss the impact of learning motivation on colleges students' English learning and the implication on college English teaching.
\end{abstract}

\section{The Functions and Characteristics of Learning Motivation}

\subsection{The function of guiding learning.}

In the classroom, learning motivation as a compass and a steering wheel, guide the students' learning direction and make learning always advance toward the intended learning goals. On the one hand, it can make students pay attention to some things and ignore other things so that students can produce a selective perception. As the saying goes that optimistic people always notice that half of the teacup is full, and what pessimists notice is that half of the teacup is empty. If college students have strong motivation to improve their English, they will often focus on relevant aspects of the curriculum and examination ignoring other aspects of learning content; on the other hand, learning motivation also affects students' interpretation of their own learning. For the same kind of learning, students with different learning motivations tend to make different interpretations.

\subsection{The function of promoting learning.}

In a certain range, learning motivation has significant correlation with learning performance. Under the condition of equal levels of wisdom, students with higher achievement motivation and ambition do better in their learning than those with lower achievement motivation and ambition. In addition, experiments prove that, one of the reasons for the poor performance of students is that most of them can not forming a good habit of focus their attention on learning and the range of their attention is narrow and unstable, which are often because their learning motivations have not been fully stimulated. Its function of promoting learning is mainly realized by mean of strengthening attention and improving thinking positively.

\subsection{The function of arousing psychological states.}

In classroom teaching, intellectual factors, such as observation, memory, imagination, thinking ability have direct and important influences on learning. However, some non-intellectual factors, such as qualities of focusing their attention on learning, resisting frustrations and persistence are essential for the success of learning. Learning motivation can appeal to a state of readiness to enhance these important qualities to promote learning indirectly. For example, a student with a 
strong motivation to learn the best, he will always keep his attention in the learning in the classroom, reducing other related activities, persevering, eliminating interference and overcoming difficulties, failures and setbacks and at last, achieve his aim.

\subsection{The function of maintaining learning activities.}

Students learning activities are brain work, and learning motivation plays an irreplaceable role in maintaining learning activities in cognitive areas effectively for a long time. Through the above analysis, such a conclusion can be drawn : learning motivation plays a positive and great part in the classroom teaching. Therefore, according many scholars, learning motivation is learning catalyst and should become the one of the important measures of teaching evaluation.

\section{The Main Factors Influencing College English Learning Motivations}

\subsection{Cognitive factors}

According to the Garner. R \& Lambert, learning motivations can be divided into integrative motivation and instrumental motivation. English learners have their different understandings of learning English, so they have differences in English learning motivations. Some of them learn English for effective communication with native speakers, learning in the target language and culture to become a member of them. And for most Chinese English learners, they learn English mainly in order to pass the exam, obtain the diploma, Diploma, scholarships, certificates of band 4 or band 6 of cet exams, promotion, entrance or only affirmation and praise from their parents and teachers. Students with Instrumental motivations tend to be in the passive learning. They have not enough self-cognition to understand their own disadvantages and their knowledge is not abundant to form good learning habits and methods, which often makes their achievements unsatisfactory.In the classroom,such students are not positive enough and their classroom participation is not conscious. They would be frustrated and lose their own interests and hobbies in English learning, once their goals can be realized. Most of college students hold instrumental learning motivation in their English learning which is not effective enough to improve college students' English learning and change their passive position. Therefore, it is necessary to cultivate college students' integrative motivation and stimulate their positive learning motivations and interest in English learning.

\subsection{Emotional factors}

Emotional factors also play a key role in learning motivation. Emotional change will cause the change of the motivation,so emotional factors and learning motivations are closely related to each other. Emotions include interest, attitude, self-confidence and anxiety and the like. From the perspective of interest, some students, especially boys, are not interested in language learning and there is no exception to English as a foreign language, and thus English learning itself would become something unpleasant for them, which causes them to lack the enthusiasm of autonomous learning and negative attitude toward English learning. Under such circumstances, no one can expect them to engage in learning English. At the same time, interest often determines and affect the attitude of learning English. Positive attitude toward a foreign language often come with keen and vice versa. Confidence is very important for the success of English learners and it will undoubtedly help students learn English better, and the lack of confidence will make students with poor performance further reduce the their learning initiative. Anxiety, regardless of successful learners and unsuccessful learners exists and play a role for them, but anxiety can promote some to study well while for other, anxiety can impede their learning effect.

\subsection{Social and environmental factors}

In terms of social factors, students' learning motivation of English learning can be influenced by the social environment, mainly reflected in aspects: the social demand for English learners, the status of them in society, the degree of being recognized, the role played for the society and their personal values and social values, all of which can determine college students' learning motivation of English. In an society where communication in English plays an important role, English learners can have strong motivations than those in the society English is not stressed. Environmental factors includes geographical environment and learning environment. As for the former, big cities can provide better learning atmosphere, facilities, and conditions than remote areas.. Similarly, the 
favorable learning environment, such as speech room, multimedia, multi-function classrooms can encourage learners to improve more English learning motivation than poor facilities.

\subsection{Teachers' factors}

The role of teachers' factors on learning motivations can not be ignored. If English teachers are qualified and well-trained enough, students' learning motivations can be aroused enthusiastically. Good English teachers should have qualities in their aptitude, teaching experience, teaching attitude, teaching goals, teaching content focused, reasonable level, diversification of teaching methods and can cater to their students' demands from various angles and their teaching programs should be adjusted according to the students' majors, learning competence and learning performance to effectively cultivate students' interest in learning, and create a vivid, lively, interesting atmosphere in the classroom. Only in this way, can students' learning motivation be enhanced greatly. Otherwise poor English teachers will have a negative impact on college students' English learning motivations.

\section{The Implications on College English Teaching}

Through the study and analysis of learning motivations above, it can be seen that learning motivations are influenced by many factors. To study and research factors influencing English learning motivations, it is helpful to understand the nature of foreign language learning deeply, so as to select the effective teaching strategies to better stimulate students' English learning motivations. In teaching, college English teachers can use the following strategies to stimulate students' English learning motivation.

\subsection{Helping the students to set up the correct goals of English learning}

Students should understand they need not only long-term goals but also short-term goals in their English learning. The long-term goals are set for a long time, such as two years or even longer period of time to learn English. The short-term goals are actually stage goals. To achieve the goal in a certain stage of English learning is to realize the the long-term goal better. The short-term goals can ensure that students obtain steady progress, which is helpful to improve their confidence. At the same time, the teachers should guide the students to set the goals which should be realistic. Those which do not conform to the actual target, not only cannot be achieved, but also increase the students' anxiety in learning English and lead them to lose their self-confidence.

\subsection{Correcting students attitude toward college English learning}

Students' attitude towards language learning is affected to a large extent by the values of the language they hold. Teachers can take the following ways to make students understand the values college English learning. College English teachers should try to help their students learn to understand the practicality of English through the introduction of the culture and customs of the English speaking countries and emphasizing the importance of English for their individual future development. Teachers can also do some investigations by some questionnaires and other methods to find out students' demands and suggestions for English learning and classroom teaching methods and based on the feedback to do some flexible adjustments. For example, College English teachers can use some games and videos to stimulate students' learning motivations.

\subsection{Guiding students to establish positive attribution theory}

To improve self-confidence of students' language learning when students make progress in English learning, teachers should emphasize their learning progress is mainly due to their efforts and hard-working rather than other factors such as good luck. Once students in learning English suffered a setback, teachers should encourage students to overcome difficulties, which doesn't mean they do not have the ability to learn English well, but they should pay more for learning. In addition, teachers can introduce examples of successful English learning to students and make them understand English learning is controllable so as to help students build up their confidence in learning English.

\subsection{Improving teachers' qualities and teaching values}

The qualities of teachers determines whether they are competent for teaching the language while teaching values can determine whether they treat their teaching seriously. These in turn, will affect the students' attitude towards language learning and motivation. Therefore, teachers should not only 
be proficient in their professional knowledge, but also have education good knowledge of psychology and other aspects. At the same time, it can be seen from factors affecting learning motivations that the traditional teaching method should be changed. The class should be students-centered and teachers should become coordinator, assistant and organizer in the class.

\section{Conclusion}

In summary, learning motivation is one of the major factors that influence college English learning. At the same time, learning motivations can be affected by many factors. Therefore, college English teachers should try to arouse their students positive learning motivations so as to promote their English learning. In short, learning motivations are essential to the success of college English learning and must be paid enough attention by teachers.

\section{References}

[1] Xiuzhi Li. Stimulating Students' Learning Motivation and Strengthening the Learning of English Listening [J]. China's New Technologies and New Products, 2009, (2)

[2] Qunli Mo. English Learning Motivation of Non-English Majors' Students and Motivating Strategies [J]. Journal of Hunan Institute of Science and Technology, 2003, (1)

[3] Maoying Xiang. The Influence of Emotional Factors on College English Teaching and Learning [J]. Foreign language and foreign language teaching. 2003 (3)

[4] Chili Li Analysis of Learning Motivation and Its Implications on College English Teaching [J]. Journal of Liaoning Administration College 2009 (9)

[5] Pingfeng Teng \&Maohua Kang The Implications of Learning Motivation on College English Teaching [J]. Legal System and Society2008 (2) 